\title{
A Data-Driven Architectural Framework for LGUs in Disaster Preparedness and Management System
}

\author{
Rosemarie T. Bigueras, Jocelyn O. Torio, and Thelma D. Palaoag
}

\begin{abstract}
Disaster preparedness and disaster management plan is one of the main concerns of the government to reduce the damage in human lives and economic loss. As a response, the researchers decided to develop a data-driven architectural framework for LGUs in Disaster Preparedness and Management System. The researchers used descriptive research method to obtain data and information in identifying the attributes needed in employing disaster preparedness and management plan for data mining processes. Qualitative research method was also used to develop the architectural framework to be designed from the identified attributes in disaster preparedness and management plan and to test the viability of the designed architectural framework in disaster preparedness and management system. Respondents of this study are the Municipal Disaster Risk Reduction Management Council (MDRRMC), Department of Agriculture (DA), Municipal Engineering Office (MEO), Municipal Social Welfare and Development (MSWD), and the Local Government Units (LGUs). Based on the assessment of the user (highest scale is 5), the developed architectural framework has weighted mean of 4.58 in terms of efficiency, effectiveness and impact which means that this will serve as a significant tool for decision making to help the LGUs to have a concrete, effective and efficient disaster preparedness and management plan based on their needs to reduce vulnerability in human lives, infrastructure and agriculture.
\end{abstract}

Index Terms-Architectural framework, data mining, disaster, disaster management plan, disaster preparedness.

\section{INTRODUCTION}

Disaster is a natural catastrophe or a sudden event which may cause great damage in agriculture, infrastructure and even the loss of human lives. The Philippines is vulnerable to this disasters, man-made or natural, such as earthquakes, typhoons, floods, fires, etc, and also one of the most disaster-prone country in the globe. The Centre for Research on the Epidemiology of Disasters (CRED) has been active for more than 40 years in doing studies in the field of international disasters and conflict health, recorded and showed that since third quarter of January 2017 (January 15 - January 21) two (2) floods has happened in two different areas in the Philippines. In the record, as of July 2017 it also shows that earthquake, typhoons and other man-made or technological disasters occurred in the Philippines. Likewise, in the study of Lagmay, A., et al, (2017) Philippines is situated where storm is common and certainly suffer from different calamities just like of those experienced before.

Manuscript received March 13, 2018; revised May 17, 2018.

The authors are with Camarines Norte State College, Camarines Norte State College, and University of Cordilleras, Philippines (e-mail: rosemariebigueras@gmail.com,_jocelynt77@gmail.com, and tpalaoag@gmail.com).
Because of the recent developments and population growth in the hazard prone areas, damages to infrastructure and human losses are expected and will even increase unless proper procedures will be implemented by the government immediately. Government agencies concerned in disaster management plan in the Philippines are seriously creating and developing disaster preparedness and management plan to reduce the impact of the disaster in the country [1]. Reducing vulnerability and enhancing resilience are the agendas priorities of disaster risk reduction (DRR) and change adaptation (CCA) (Begum, R.A., 2014) [2].

Different types of disasters could have different impact to population based on their locations, according to Bankoff, G. (2007) every location may have different vulnerabilities for every disaster and see this as a destructive one for a short term but can be a transformative agent for a longer term [3].

The study of Alcantara, P. (2014) aims to give means in case of emergency management for those in government units and administrations when it comes with dealing with disasters through implementing life-saving interventions [4]. In the Philippines, one of the agency involved in the disaster management plan is the Local Government Units (LGUs). Local Government Unit plays a vital role when it comes with emergency management through devising complete policies and procedures in responding to the community emergencies and their aftermath effectively. However, public officials find it difficult to evaluate and assess the quality of the existing emergency management programs due to rare or no existing emergency measures for government units (Henstra, D., 2010) [5].

However, the impacts of disasters to social units, from individuals, households to nation-state will be addressed by disaster studies. Factors of the history of disasters are studied in terms of the ways in which populations at risk conduct hazard and vulnerability analyses as well as plan and implement mitigation, preparedness, response, and recovery actions, Lindell (2013) [6].

Likewise, disaster preparedness and management plan is very important to reduce the vulnerability of the community. Developing information system and framework would be a great help to the authority to have a better disaster management plan. The study of Li D., et al, (2014) presented the framework for Chinese National Disaster Reduction System of Systems (CNDRSS) to provide one stop-services for all phases of disaster management and to link together existing and planned disaster-related business and observation system. They used federated databases [7].

Disaster preparedness and management plan for different type of disaster in different location will be improved using information system that facilitate data and information collection that help them for decision making in disaster 
preparedness and management plan. In this context, the researchers developed an architectural framework to develop the LGUs disaster preparedness and management system. Specifically, it sought to identify the important attributes needed in employing disaster preparedness and management plan for data mining processes, the architectural framework developed was anchored from the identified important attributes in disaster preparedness and management plan. Data from different agencies will be centralized and stored in cloud for easy update and retrieval once data mining technique will be employed. A concrete disaster preparedness and management system will be developed using the huge data coming from said agencies. Finally the viability of the designed architectural framework will be also be tested. The locales of this study is Daet, Camarines Norte, Philippines. Daet is the capital town of Camarines Norte province in Bicol Region (Region V).

The researchers believed that this study shall benefit the system developer, which will guide them to develop a concrete information system that the LGUs need for disaster preparedness and management plan. A great help to Municipal Disaster Risk Reduction Management Council (MDRRMC) for them to have a concrete disaster and management system for decision making purposes. This will also help the Barangay Disaster Risk Reduction Management Committee to improve the current disaster preparedness and management plan. This study will further increased the knowledge of the researchers itself in both conceptual views of disaster management as well as analytical and programming skills and will enhance their awareness on the social responsibilities as part of a community. Furthermore, this study may serve as a basis that shall guide the future researchers to conduct further related studies and this will also give them ideas on how to develop information systems that could benefit the community as a whole.

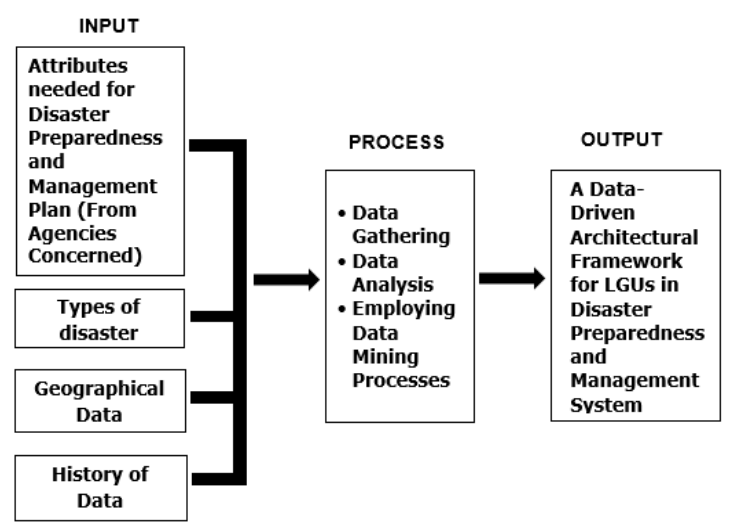

Fig. 1. Conceptual framework of the study.

\section{A. Conceptual Framework}

A Conceptual Research Framework for a Data-Driven Architectural Framework for LGUs in Disaster Preparedness and Management System is shown in Fig. 1 which followed the input-process-output model of the system. Inputs include attributes needed for disaster preparedness and management plan, types of disaster, geographical data, and historical data. Inputs will be processed through data gathering, data analysis, and employing data mining processes to come up with a data-driven architectural framework for LGUs in disaster preparedness and management system.

\section{MethodOLOGY}

The researchers used descriptive research method to obtain pieces of information and to identify the attributes needed in employing disaster preparedness and management plan for data mining processes. Using interviews and distributed questionnaire, the researchers were able to gather quantitative and qualitative data to come up with a personal description in answering research problem in identifying the attributes needed in employing disaster preparedness and management plan for data mining processes. Survey and interviews with the persons involved in disaster preparedness and management plan in Municipal Disaster Risk Reduction Management Council (MDRRMC), Municipal Social Welfare and Development (MSWD), Municipal Engineering Office (MEO), Department of Agriculture (DA), and Barangay Disaster Risk Reduction Council was administered that help the researchers to identify other important attributes needed in disaster preparedness and management plan.

Qualitative research method was used by the researchers to develop the architectural framework with the other important identified attributes in disaster preparedness and management plan and also used to evaluate and test the viability of the designed architectural framework in disaster preparedness and management system. In-depth analysis of existing architectural framework which is the Disaster CDM Architecture from the study titled "Knowledge as a Service Framework for Disaster Data Management" (Katarina Grolinger, et al, 2013) for disaster preparedness [8]. It was reviewed thoroughly to identify the difference of the proposed architectural framework from the existing framework. Weighted mean is used in this study as statistical treatment for evaluation of users in the proposed framework.

For data mining process, sentiment analysis using MS excel were used to analyze the sentiments of the respondents and also to get the important attributes to be added and included to have a concrete data-driven architectural framework for LGUs disaster preparedness and management system.

\section{RESULTS AND DISCUSSIONS}

This presents the attributes needed in preparing disaster preparedness and disaster management system, the developed architectural framework was derived from the identified attributes in disaster preparedness and management plan. Viability of the designed architectural framework in disaster preparedness and management system was evaluated.

\section{A. Attributes Needed in Disaster Preparedness and Management System}

Based on the response of the respondents of this study the researchers found out that $100 \%$ of the respondents marked the attributes such as physical and demographic characteristics of the barangay, geohazard assessment, and 
type of disaster as needed in disaster preparedness and management plan. These attributes are commonly used and currently included in their existing disaster preparedness plan since these are composed of the location, total land area, number of purok or sitio, reference point or boundaries of the barangay, total household by purok, total family per purok, the age bracket by gender of minor, household profiling, barangay geohazard assessment, mapping locations, and type of facilities that will be useful in disaster preparedness and disaster management plan in terms of identifying the type of disaster that can be experienced by a certain barangay to assess the vulnerability and risk of the barangay and to forecast the damage assessment once a barangay is affected.

Other attributes out of these common attributes found in the data sets gathered, the researchers found out that $75.86 \%$ of the respondents believed that the level of awareness of the population at risk is also needed in the disaster preparedness while $70.68 \%$ of the respondents also agreed that the status of food and non-food items in stock pile should also needed in the plan. The $51.72 \%$ and $60.34 \%$ of the respondents believed that history of data of different disasters and socioeconomic profile is also needed and which has a great significance in disaster management plan where they can use this as one of the guide on what are they going to do if the disaster of the same type happened again in their particular place to reduce the damage on life and property. Socioeconomic is also needed in the plan since they could identify the population that need more help from the government in terms of disaster preparedness and disaster mitigation. The $53.45 \%$ of the respondents believed that household and business zoning while $94.79 \%$ of the respondents believed that and the information and communication technology is also needed in disaster preparedness and management plan since they believed that these two would be a great help in planning. Likewise, $63.79 \%$ of the respondents believed that crop and animal information is also needed to be able to identify the damage that might happen on their area. The researchers included these all attributes that was identified by the respondents in the development of the architectural framework for LGUs disaster preparedness and management system for a more comprehensive, concrete and effective disaster preparedness and management system for Local Government Units. It is stated in the study of Scolobig, A., et al, (2012) that the improvement of residents' knowledge about their environment and the residual risk seemed to be crucial to increase risk awareness, and the same was true for the strengthening of local support networks to foster preparedness [9]. Level of awareness in terms of disaster preparedness of population at risk is needed in disaster preparedness and management plan to be able to identify the need of trainings or seminars on disaster preparedness of the population. Updated inventory of stock of food and nonfood items in stock file of DSWD should be able to identify in order to have proper allocation of funds in disaster response. It will also serve as a guide to disaster management plan if the LGU needs the support of other agencies in terms of relief distribution. In a report of Commission on Audit (COA) for 2015, a sound relief of goods inventory system was not established at the DSWD resulting in the spoilage of the foods. Moreover, erroneous recording of such inventory under financial assistance to Non-Government Agencies (NGAs) instead of welfare goods for distribution inventory resulted to misstatement of both accounts [10]. History of data is needed in disaster preparedness to assess the gap that happened from previous disaster happened in the locality to avoid it to happen again. Guha-Sapir, D., and Below, R. (2002) stated that high quality historical data is required to justify resource allocation, establish risk and vulnerability and undertake comparative analyses between regions [11]. According to the MDDRM Officer, the information of household zoning coming from the Municipal Planning Development is one of the attributes needed in disaster preparedness and management plan to identify if the location of the family is at risk or identify the vulnerability, to be able to identify the exact location of the affected family or individuals in certain locations as well as to identify the socio-economic damage of each family affected. Business zoning is needed to identify if the business location of certain business is located in disaster prone area on certain disaster and also this information is needed for damage assessment after disaster occur if the business establishment was affected by the disaster

Dr. Mohammad Arif Kamal, (2015) stated that the advancement in Information and Communication Technology in the form of Internet, GIS, Remote Sensing, Satellite communication, etc. can help in planning and implementation of disaster management [12]. Information and communication technology (ICT) is one of the attributes that should be included by the Local Government Unit in disaster preparedness and disaster management system. ICT will help the LGU and other agencies involved to collect and disseminate information that needed in disaster management plan such as the demographic profiles. This information technology could also help the LGU to retrieve and have a collaborative sharing of all history of data related to past disaster from different agencies that is one of the information needed in disaster.

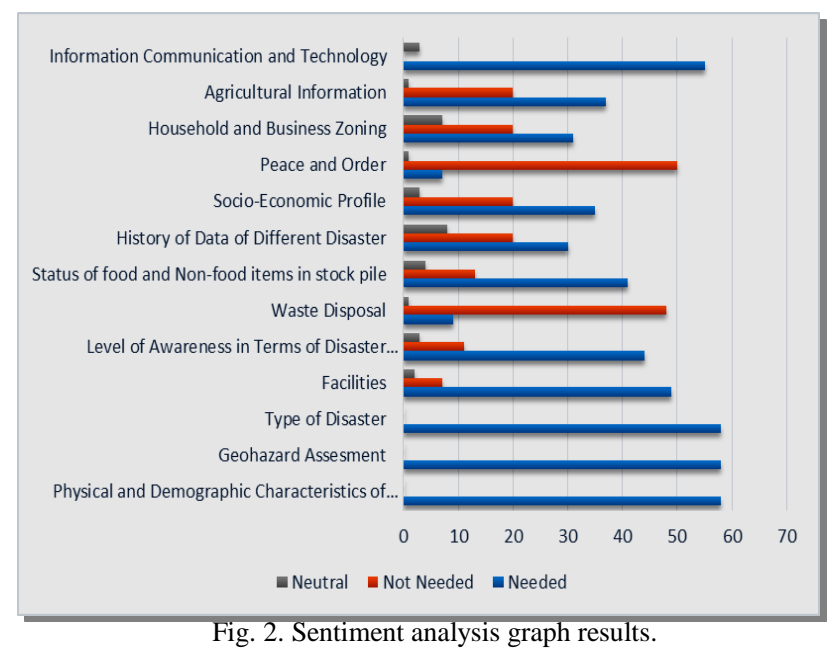

The researchers used the sentiment analysis using excel application to find out the sentiments of the respondents on what and which important attributes needed and should be included in the LGU preparedness and management plan. Fig. 2 shows that attributes such as peace and order and waste disposal is more of not needed which means that most 
of the respondents believed that waste disposal and peace and order in certain areas are not needed in disaster preparedness and management plan since they believed that before and during disaster the population at risk is manageable. Other respondents who did not identify the attributes needed or not needed means that they are neutral, most of the respondents who identified the different attributes believed that it should be included in disaster preparedness and management plan.

Attributes such as type of disaster, facilities, geohazard assessment, and physical and demographic characteristics of the barangay were already included in the current disaster preparedness and management plan. With these results, the researchers decided to identify unique attributes, shown in Table I, based on the analysis that those with high rate on needed attributes should also be included in the plan.

\section{B. Architectural Framework Designed from the Identified Attributes in Disaster Preparedness and Management Plan}

The developed LGUs - DPM Architectural Framework is shown in Fig. 3 where the framework shows the different attributes needed in disaster preparedness and management plan. It composed of data sources, cloud storage, data processing and the output.

TABLE I: IDENTIFIED UNIQUE ATTRIBUTES

\begin{tabular}{llccc}
\multicolumn{1}{c}{ Attributes } & Needed & $\begin{array}{c}\text { Not } \\
\text { Needed }\end{array}$ & Neutral & $\begin{array}{c}\text { Sentiment } \\
\text { Analysis }\end{array}$ \\
\hline $\begin{array}{l}\text { Level of awareness in } \\
\text { terms of disaster } \\
\text { preparedness of } \\
\text { population at risk }\end{array}$ & 44 & 11 & 3 & Needed \\
\hline $\begin{array}{l}\text { Status of food and } \\
\text { non-food items in } \\
\text { stock pile }\end{array}$ & 41 & 13 & 4 & Needed \\
\hline $\begin{array}{l}\text { History of data of } \\
\text { different disasters }\end{array}$ & 30 & 20 & 8 & Needed \\
\hline $\begin{array}{l}\text { Socio-economic } \\
\text { profile }\end{array}$ & 35 & 20 & 3 & Needed \\
\hline $\begin{array}{l}\text { Household and } \\
\text { Business Zoning }\end{array}$ & 31 & 20 & 7 & Needed \\
\hline $\begin{array}{l}\text { Agriculture (Crop } \\
\text { and Animal) } \\
\text { Information }\end{array}$ & 37 & 20 & 1 & Needed \\
\hline $\begin{array}{l}\text { Information } \\
\text { Communication and } \\
\text { Technology (ICT) } \\
\text { integration }\end{array}$ & 55 & 0 & 3 & Needed \\
\hline \hline
\end{tabular}

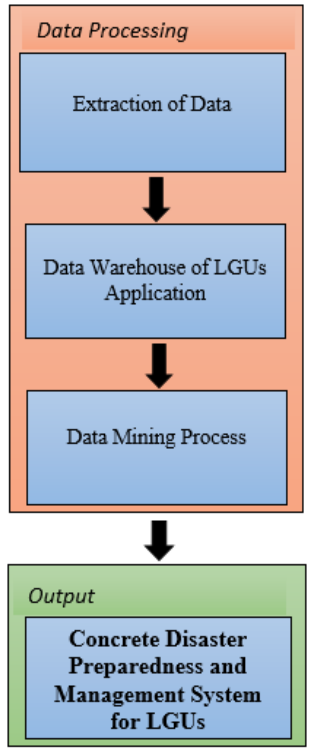

Fig. 3. LGUs - DPM architectural framework.
Data Sources. The data sources of the LGUs - DPM Architectural Framework are coming from different agency involved such as Barangay Disaster Risk and Reduction Management Council (BDRRMC), National Disaster Risk and Reduction Management Council (NDRRMC), Municipal Department of Agriculture (MDA), Municipal Disaster Risk and Reduction Management Council (MDRRMC), Municipal Social and Welfare Development (MSWD) and Municipal Engineering Office (MEO). Each agency will see the different attributes that is needed in disaster preparedness and management plan of LGU. Each agency must have their own database management system that store the different information of their agency and other information and communication technology. The database of the agency involved should be connected to the cloud storage of the LGU.

Cloud Storage. The cloud storage served as the data storage of this proposed framework, it will served as a consolidated data source to have a collaboration of data in different agencies. The cloud environment of the proposed framework composed of NoSQL database since the different data coming from agency is heterogeneous and big data. NoSQL database is the latest generation of database, this type of database will cope the disadvantages of the relational database in big and heterogeneous data.

Data Processing. The processing of data in the proposed framework started from data retrieval coming from LGU cloud storage then all information that are related to disaster preparedness and management plan will be extracted, the framework will use any third party software for extraction of data coming from the consolidated cloud storage. Once the information is already extracted, it will then be saved to local data warehouse of the LGU. The framework will still be using the data warehouse since the information extracted coming from the cloud is not fully classified and still a big data. From the data warehouse of the LGU the data mining 
process such as prescriptive techniques could be used to have a better concrete disaster preparedness and management plan system. The prescriptive data mining techniques will help the LGUs to forecast the necessary data in terms of disaster preparedness, mitigation, response and recovery. It will also help the LGU to identify the impact of the disaster on specific location and to the affected population. It will also identify the estimation cost of the damage in terms of infrastructure and agriculture.

The framework stayed in the decentralized database for every agency for the purpose that the agency still can use their own information system without the connection to the internet.

\section{Viability of the Designed Architectural Framework in Disaster Preparedness and Management System}

Viability of the designed or developed architectural framework in the disaster preparedness and management system was done through comparing and contrasting existing framework for disaster management which are disaster-CDM architecture. Data storage, data processing, document or data sources and the user of the framework are the criteria used to compare the two framework since these attributes are basic components in comparing different architectural frameworks finally, evaluation of the designed framework was also conducted to know how users are satisfied.

\section{Disaster-CDM architecture}

The disaster-CDM architecture is shown in Fig. 4, wherein it shows the inclusion of different data processing methods such as text extraction, file metadata separation, pattern processing, simulation model, etc., to get the desired output to be forwarded to the cloud storage. In the cloud storage, several databases such as relational, document, column-family, and graph databases were used for a knowledge-as-a-service for a disaster data management, they provided interface to the users to be able to view or access the data in the cloud storage.

Comparing the two frameworks, CDM Architecture used the cloud environment as storage that composed of NoSql and relational database while in LGUs DPM architectural framework the cloud storage used only NoSql database and retained the relational database in local database management system of the agencies involved to be able to access the data by respective agencies.

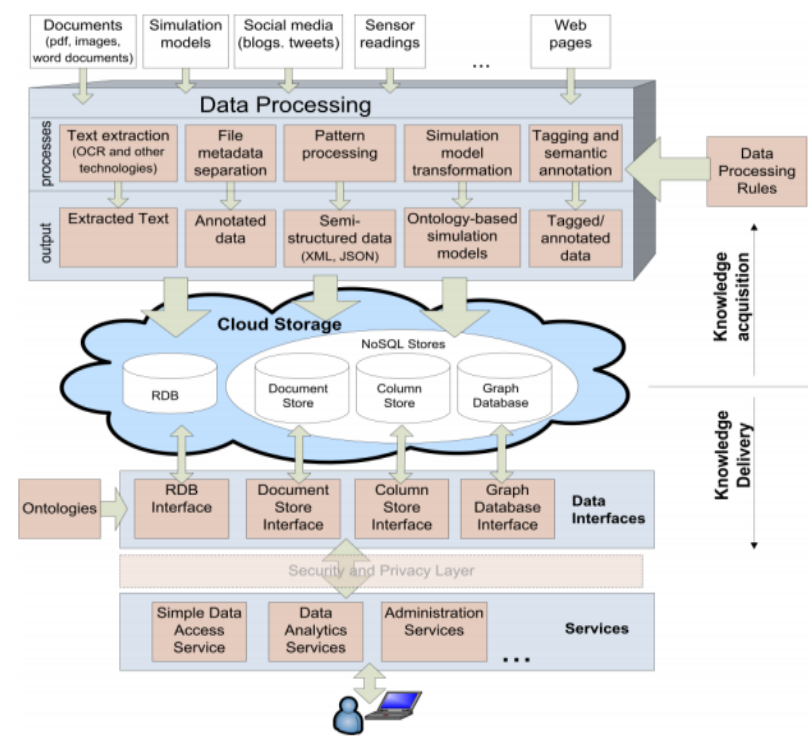

Fig. 4. Disaster - CDM architecture.

In terms of data processing the CDM framework applied the data processing before it store in the cloud storage to be able to understand by their target user while in LGUs DPM architectural framework, the data processing such as extraction and retrieval of data is done coming from the cloud storage, the purpose of this is to make sure that all data needed in disaster management plan coming from different agencies shall be included in the disaster preparedness and management plan, after extraction using the third party, it will store to another storage which is the local data warehouse of the LGU then the data mining process techniques will be applied to have a concrete disaster preparedness and management plan. In terms of data sources the LGUs DPM architectural framework used only the data source of different agencies involved in disaster while the CDM use the web and social media as their data source. In terms of users the CDM did not specify who their users are while the DPM has intended only for the LGU Disaster Management Council for their disaster preparedness and management plan. Table II shows the summarized comparison of the framework.

TABLE II: COMPARISON OF DISASTER - CDM ARCHITECTURE AND LGUS DPM ARCHITECTURAL FRAMEWORK

\begin{tabular}{|c|c|c|c|c|}
\hline Frame-work & Storage & Data Processing & $\begin{array}{l}\text { Documents/ } \\
\text { Data Sources }\end{array}$ & User \\
\hline $\begin{array}{l}\text { Disaster- } \\
\text { CDM } \\
\text { Architecture }\end{array}$ & $\begin{array}{l}\text { Cloud Environment with } \\
\text { NoSQL and Relational Database }\end{array}$ & $\begin{array}{l}\text { Data Processing Rules } \\
>\text { Cloud Storage }>\text { User }\end{array}$ & $\begin{array}{ll}\text { Web, } & \text { Word } \\
\text { Documents } \\
\text { Social Media }\end{array}$ & No Specific User \\
\hline $\begin{array}{l}\text { LGUs DPM } \\
\text { Architectural } \\
\text { Frame work }\end{array}$ & $\begin{array}{l}\text { Cloud Environment } \\
\text { NoSQL and Local Relational } \\
\text { Database in each } \\
\text { Involved }\end{array}$ & $\begin{array}{l}\text { Data Source } \\
\text { >Cloud Storage } \\
\text { > Extraction of Data } \\
\text { > Store in Data Warehouse of LGUs } \\
\text { >Apply Data Mining >Disaster } \\
\text { Management Plan }\end{array}$ & $\begin{array}{lr}\text { Information } & \text { System } \\
\text { of } & \text { Individual } \\
\text { Agencies } & \text { that } \\
\text { Involved } & \end{array}$ & $\begin{array}{l}\text { Intended for LGUs, and } \\
\text { other agency that } \\
\text { involved in disaster } \\
\text { preparedness } \\
\text { management plan }\end{array}$ \\
\hline
\end{tabular}

The researcher administered evaluation of the DPM Architectural framework for the respondents to evaluate the proposed architectural framework

Table III shows the summary of assessment of user who evaluated the architectural framework designed by the researchers. Using weighted mean as the statistical treatment applied, it shows that indicators like efficiency has an average weighted mean of 4.64, effectiveness has 4.6, and impact has 4.51. These three (3) indicators have an average weighted mean of 4.58 with an interpretation of very satisfied. This scale falls under the highest rating which range from 4.01-5.0 (Very Satisfied), 3.01-4.0 (Satisfied), 2.01-3.0 (Partly Satisfied), 1.01-2.0 (Dissatisfied), and 0.011.0 (Very Dissatisfied). 
TABLE III: SUMMARY OF ASSESSMENT OF USER

\begin{tabular}{llc}
\hline \multicolumn{1}{c}{ Indicators } & Mean & Interpretation \\
\hline Efficiency & 4.64 & Very Satisfied \\
\hline Effectiveness & 4.6 & Very Satisfied \\
\hline Impact & 4.51 & Very Satisfied \\
\hline Average Weighted Mean & $\mathbf{4 . 5 8}$ & Very Satisfied \\
\hline \hline
\end{tabular}

\section{CONCLUSION}

In previous years, Philippines have witnessed numerous extreme natural disasters as well as man-made disasters. At the same time, there is no existing concrete framework in disaster preparedness and management for every local government unit who plays a vital role in emergency management through developing policies and procedure to respond effectively to community during emergencies.

This paper shall present the important attributes that need to be included in disaster preparedness and management system to be able to have better framework for LGUs disaster preparedness and management plan. The proposed framework will be a great help to the LGUs in disaster management plan in terms of disaster mitigation, preparedness, response and recovery. This will also help the LGUs and other agencies involved in disaster planning to collaborate with each other to be able to reduce the vulnerability and impact of the disaster to human lives and to the government. They can use it in decision making support and even in the prediction of any disaster-related interventions. The framework developed in this paper is effective, efficient, and with great impact to achieve the country's overall disaster risk reduction management vision which is "safer, adaptive and disaster-resilient Filipino communities toward sustainable development." The outlook for further research will be the development of that concrete disaster preparedness and management system for LGUs.

\section{ACKNOWLEDGMENT}

This research was made possible through the untiring support of the Municipal Disaster Risk Reduction Management Council (MDRRMC) of the municipality of Daet, Camarines Norte (Region 5) Philippines.

\section{REFERENCES}

[1] A. M. F. A. Lagmay, B. A. Racoma, K. A. Aracan, J. Alconis-Ayco, and I. L. Saddi, "Disseminating near-real-time hazards information and flood maps in the Philippines through Web-GIS," Journal of Environmental Sciences, 2017.

[2] R. A. Begum, M. S. K. Sarkar, A. H. Jaafar, and J. J. Pereira, "Toward conceptual frameworks for linking disaster risk reduction and climate change adaptation," International Journal of Disaster Risk Reduction, vol. 10, pp. 362-373, 2014.

[3] G. Bankoff, "Comparing vulnerabilities: Toward charting an historical trajectory of disasters," Historical Social Research/Historische Sozialforschung, pp. 103-114, 2007.

[4] P. Alcantara, "Lessons learned from the Philippine government's response to typhoon Haiyan," Journal of Business Continuity \& Emergency Planning, vol. 7, no. 4, pp. 335-346, 2014.

[5] D. Henstra, "Evaluating local government emergency management programs: What framework should public managers adopt?" Public Administration Review, vol. 70, no. 2, pp. 236-246, 2010.

[6] M. K. Lindell, "Disaster studies," Current Sociology, vol. 61, no. 5-6, pp. 797-825, 2013

[7] D. Li, L. Zeng, N. Chen, J. Shan, L. Liu, Y. Fan, and W. Li, "A framework design for the Chinese National Disaster Reduction
System of Systems (CNDRSS)," International Journal of Digital Earth, vol. 7, no. 1, pp. 68-87, 2014.

[8] K. Grolinger, M. A. Capretz, E. Mezghani, and E. Exposito, "Knowledge as a service framework for disaster data management," in Proc. 2013 IEEE 22nd International Workshop on Enabling Technologies: Infrastructure for Collaborative Enterprises (WETICE) (pp. 313-318).

[9] A. Scolobig, B. De Marchi, and M. Borga, "The missing link between flood risk awareness and preparedness: Findings from case studies in an alpine region," Natural Hazards, vol. 63, no. 2, pp. 499-520, 2012.

[10] Consolidated report on the Audit of the Disaster Risk Reduction Management (DRRM) Fund. [Online]. Available: https://www.coa.gov.ph/.../DRRM/Consolidated_Report_of_DRRM_ Fund CY2015.pdf

[11] D. Guha-Sapir and R. Below, "The quality and accuracy of disaster data: A comparative analyse of 3 global data sets," Disaster Management Facility, vol. 191, 2002.

[12] M. A. Kamal, "Role of information and communication technology in natural disaster management in India," ICT in Disaster Management, pp. 182-188, 2015

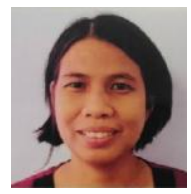

Rosemarie T. Bigueras was born in Daet, Camarines Norte, Philippines on January 16, 1978. She finished her baccalaureate degree of bachelor of science in computer science in Bicol University, Legazpi City, Philippines on March 1999. On May 2015, she finished her master's degree of master in information technology in University of Cordilleras, Baguio City, Philippines. Currently, she is enrolled in the program doctor of information technology under the graduate scholarships in the $\mathrm{K}$ to 12 transition program of CHED in University of Cordilleras, Baguio City, Philippines.

She is currently connected as an assistant professor of Camarines Norte State College in Daet, Camarines Norte, Philippines. She's been in the government service for fifteen (15) years and teaching IT Subjects. Her research interests are system development, information system, computer education, natural language processing, etc.

Assistant Professor Bigueras is an active member of Philippine Society of Information Technology Educators in Region V.

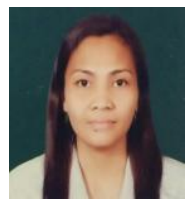

Jocelyn O. Torio was born in Daet, Camarines Norte, Philippines on December 19, 1977. She finished her baccalaureate degree of bachelor of science in computer engineering in Adamson University, Manila, Philippines on April 1999. Last March 2015, she finished her master's degree of master of information technology in Ateneo de Naga University, Naga City, Philippines. Currently, she is enrolled in the program doctor of information technology under the graduate scholarships in the $\mathrm{K}$ to 12 Transition program of CHED in University of Cordilleras, Baguio City, Philippines.

She is currently connected as an assistant professor of Camarines Norte State College in Daet, Camarines Norte, Philippines. She's been in the government service for fifteen (10) years and teaching IT Subjects. Her research interests are internet of things, information system, computer education, natural language processing, etc.

Assistant Professor Torio is an active member of Philippine Society of Information Technology Educators in Region V.

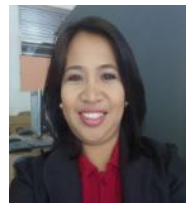

Thelma D. Palaoag was born in Baguio City, Philippines. She finished her baccalaureate degree of bachelor of science in computer science in University of Cordilleras, Baguio City, Philippines on 1998. She finished doctor of information technology in University of Cordilleras, Baguio City, Philippines.

She is currently connected as a professor in University of Cordilleras in Baguio City, Philippines. Her research interests are affective computing, machine learning, internet of things, information system, computer education, natural language processing, data mining, etc.

Doctor Palaoag is an active researcher of University of Cordilleras, Baguio City, Philippines. 